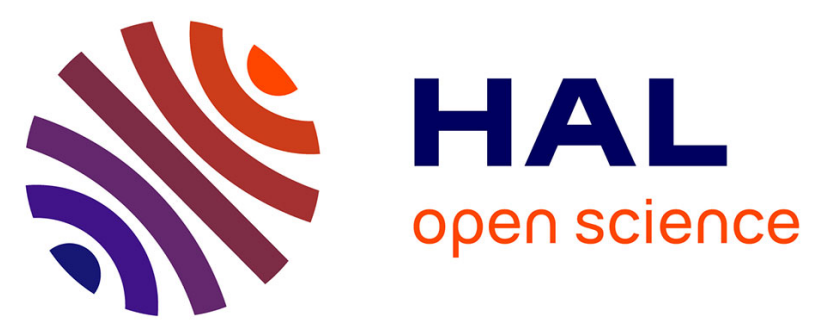

\title{
On the crystallization behavior of syndiotactic-b-atactic polystyrene stereodiblock copolymers, atactic/syndiotactic polystyrene blends, and aPS/sPS blends modified with sPS-b-aPS
}

Liana Annunziata, Bernard Monasse, Paola Rizzo, Gaetano Guerra, Michel Duc, Jean-François Carpentier

\section{To cite this version:}

Liana Annunziata, Bernard Monasse, Paola Rizzo, Gaetano Guerra, Michel Duc, et al.. On the crystallization behavior of syndiotactic-b-atactic polystyrene stereodiblock copolymers, atactic/syndiotactic polystyrene blends, and aPS/sPS blends modified with sPS-b-aPS. Materials Chemistry and Physics, 2013, 141 (2-3), pp.891-902. 10.1016/j.matchemphys.2013.06.020 . hal-00846354

\section{HAL Id: hal-00846354 https://hal.science/hal-00846354}

Submitted on 19 Jul 2013

HAL is a multi-disciplinary open access archive for the deposit and dissemination of scientific research documents, whether they are published or not. The documents may come from teaching and research institutions in France or abroad, or from public or private research centers.
L'archive ouverte pluridisciplinaire HAL, est destinée au dépôt et à la diffusion de documents scientifiques de niveau recherche, publiés ou non, émanant des établissements d'enseignement et de recherche français ou étrangers, des laboratoires publics ou privés. 


\title{
On the Crystallization Behavior of Syndiotactic-b-Atactic Polystyrene Stereodiblock Copolymers, Atactic/Syndiotactic Polystyrene Blends, and aPS/sPS Blends Modified with sPS- $b$-aPS
}

Liana Annunziata, ${ }^{\mathrm{a},{ }^{*}}$ Bernard Monasse, ${ }^{\mathrm{b},{ }^{*}}$ Paola Rizzo, ${ }^{\mathrm{c}}$ Gaetano Guerra, ${ }^{\mathrm{c}}$ Michel Duc ${ }^{\mathrm{d}}$ and Jean-François Carpentier ${ }^{\mathrm{a}, *}$

a Organométalliques et Catalyse, UMR 6226 Sciences Chimiques CNRS-Université de Rennes 1, Campus de Beaulieu, F-35042 Rennes Cedex (France)

b Mines-ParisTech, CEMEF, Centre de Mise en Forme des Matériaux, UMR CNRS 7635, Sophia Antipolis, France

c Dipartimento di Chimica e Biologia, Università degli studi di Salerno, Via Ponte don Melillo, I-84084 Fisciano (SA), Italy.

${ }^{\mathrm{d}}$ Total Petrochemicals Research Feluy, Zone Industrielle Feluy C, B-7181 Seneffe (Belgique)

E-mail: jean-francois.carpentier@univ-rennes1.fr; bernard.monasse@ mines-paristech.fr, liana.annunziatta@univ-rennes1.fr

\begin{abstract}
Crystallization and morphological features of syndiotactic- $b$-atactic polystyrene stereodiblock copolymers (sPS- $b$-aPS), atactic/syndiotactic polystyrene blends (aPS/sPS), and aPS/sPS blends modified with sPS- $b$-aPS, with different compositions in aPS and sPS, have been investigated using differential scanning calorimetry (DSC), polarized light optical microscopy (POM) and wide angle X-ray diffraction (WAXRD) techniques. For comparative purposes,
\end{abstract}


the properties of parent pristine sPS samples were also studied. WAXRD analyses revealed for all the samples, independently from their composition (aPS/sPS ratio) and structure (blends, block copolymers, blends modified with block copolymers), the same polymorphic $\beta$ form of sPS. The molecular weight of aPS and sPS showed opposite effects on the crystallization of 50:50 aPS/sPS blends: the lower the molecular weight of aPS, the slower the crystallization while the lower the molecular weight of sPS, the faster the crystallization. DSC studies performed under both isothermal and non-isothermal conditions, independently confirmed by POM studies, led to a clear trend for the crystallization rate at a given sPS/aPS ratio (ca. 50:50 and 20:80): sPS homopolymers > sPS-b-aPS block copolymers $\sim$ sPS/aPS blends modified with sPS- $b$-aPS copolymers $>$ sPS/aPS blends. Interestingly, sPS- $b$-aPS block copolymers not only crystallized faster than blends, but also affected positively the crystallization behavior of blends. At 50:50 sPS/aPS ratio, blends (Blend-2), block copolymers (Cop-1) and blends modified with block copolymers (Blend-2-mod) crystallized via spherulitic crystalline growth controlled by an interfacial process. In all cases, an instantaneous nucleation was observed. The density of nuclei in block copolymers $\left(160,000-190,000\right.$ nuclei.mm $\left.{ }^{-3}\right)$ was always higher than that in blends and modified blends $\left(30,000-60,000\right.$ nuclei. $\left.\mathrm{mm}^{-3}\right)$, even for quite different sPS/aPS ratio. At 20:80 sPS/aPS ratio, the block copolymers (Cop-2) preserved the same crystallization mechanism than at 45:55 ratio (Cop-1). On the other hand, the 20:80 sPS/aPS blend (Blend-4) and blend modified with block copolymers (Blend-4-mod) showed a spinodal decomposition.

Keywords: polymers; crystallisation; differential scanning calorimetry (DSC); optical microscopy; thermal properties 


\section{Introduction}

Atactic polystyrene (aPS), a classical commodity amorphous polymer, is widely used in many application fields because of its low density, good hydrostatic resistance and good electrical properties; this polymer shows, however, poor chemical resistance, especially against organic solvents [i]. On the other hand, syndiotactic polystyrene (sPS) is a crystalline polymer that shows many excellent properties, including good chemical resistance against common organic solvents [ii]. sPS and aPS feature quite similar mechanical properties but they differ in their optical and thermal (and therefore thermo-mechanical) properties; for instance, aPS is transparent and has a softening point of about $90{ }^{\circ} \mathrm{C}$, while sPS is opaque and has a melting point of ca. $270{ }^{\circ} \mathrm{C}$. Due to the large compatibility of aPS and sPS, optical and thermal properties of PS can be adjusted by varying the concentration of the pure components in blends. For that reason, sPS/aPS blends have been widely studied, essentially with the aim to overcome the weak properties of aPS by blending it with small amounts of sPS [Erreur ! Signet non défini.,iii,iv]. Yet, in most cases, blending of small amounts of sPS with aPS resulted in a depression of the melting $\left(T_{\mathrm{m}}\right)$ and crystallization $\left(T_{\mathrm{c}}\right)$ temperatures of $\mathrm{sPS}$ [Erreur ! Signet non défini.]. Thus, the search for suitable conditions to obtain such blends where the crystallinity of sPS would be preserved remains of upmost interest from an industrial point of view.

Recently, some of us have reported the synthesis and characterization of thus far unprecedented well-defined sPS- $b$-aPS stereodiblock copolymers [v]. Preliminary thermal studies suggested that these stereodiblock copolymers crystallize faster than the corresponding sPS/aPS blend (i.e., blends with similar syndiotactic/atactic fractions and molecular weights of each component). More interestingly, the thermal properties of sPS were preserved also for stereodiblock copolymers samples containing only $10-20 \%$ of sPS. These promising results prompted us to initiate a systematic study of the thermal properties of these new materials and to compare them with those of their corresponding sPS/aPS blends. In 
addition, we set out to explore the effect of the addition of sPS- $b$-aPS stereodiblock copolymers in regular aPS/sPS blends. For comparison purposes, the thermal properties of pristine sPS homopolymers were also investigated. Herein we report the results of nonisothermal and isothermal crystallization studies of pure sPS and of sPS in new sPS- $b$-aPS stereodiblock copolymers, in aPS/sPS blends, and in sPS/aPS blends modified with sPS- $b$ aPS copolymers. Polarized optical microscopy (POM) and wide-angle X-ray diffractometry (WAXRD) were also used to complete these studies.

\section{Materials and Methods}

The molecular characteristics of the polymers used in the present work are reported in Table 1. Syndiotactic polystyrene samples sPS-1 and sPS-3 were synthesized using $\mathrm{Cp}^{*} \mathrm{TiBn}_{3} /$ $\mathrm{B}\left(\mathrm{C}_{6} \mathrm{~F}_{5}\right)_{3}$ as catalytic system [vi] under different polymerization conditions (sPS-1: [Ti] =[B] $=44 \mu \mathrm{mol} ;[\mathrm{Ti}] /[\mathrm{St}]=1: 1000,2{ }^{\circ} \mathrm{C}, 35 \mathrm{~mL}$ toluene, $12 \mathrm{~min} ; \mathrm{sPS}-3:[\mathrm{Ti}]=[\mathrm{B}]=132 \mu \mathrm{mol}$; $[\mathrm{Ti}] /[\mathrm{St}]=1: 65,20{ }^{\circ} \mathrm{C}, 38 \mathrm{~mL}$ toluene, $\left.5 \mathrm{~min}\right)$. Sample sPS-2 was synthesized using the $\left(\mathrm{Me}_{3} \mathrm{SiC}_{5} \mathrm{Me}_{4}\right) \mathrm{Sc}\left(\mathrm{CH}_{2} \mathrm{SiMe}_{3}\right)_{2}(\mathrm{THF}) /\left[\mathrm{Ph}_{3} \mathrm{C}\right]\left[\mathrm{B}\left(\mathrm{C}_{6} \mathrm{~F}_{5}\right)_{4}\right]$ catalytic system [vii], using the following polymerization conditions: $[\mathrm{Sc}]=[$ trityl borate $]=21 \mu \mathrm{mol} ;[\mathrm{Sc}] /[\mathrm{St}]=1: 1000,25$ ${ }^{\circ} \mathrm{C}, 14 \mathrm{~mL}$ toluene, $2 \mathrm{~min}$. Atactic polystyrene (aPS) samples were provided by Total Petrochemicals and used as received. The sPS- $b$-aPS stereodiblock copolymers (Cop-1 and Cop-2) were synthesized according to the recently reported literature procedure [Erreur ! Signet non défini.]. sPS and sPS- $b$-aPS samples were purified by at least one re-precipitation

\section{in acidic methanol from dilute solutions in 1,2,4-trichlorobenzene (TCB).}

All blends were prepared using the "solution mixture" procedure reported in the literature [4a]: the proper amount of sPS, aPS and, when necessary sPS- $b$-aPS, were dissolved at $130{ }^{\circ} \mathrm{C}$ in TCB to form $3 \mathrm{wt} \%$ solutions. The resulting solutions were then casted onto a stainless dish warmed at $200{ }^{\circ} \mathrm{C}$ to rapidly evaporate TCB. Finally, the blends were kept in a vacuum oven at $150{ }^{\circ} \mathrm{C}$ for $24 \mathrm{~h}$ before characterization. For comparative purposes, sPS and 
aPS homopolymers and the aPS- $b$-sPS stereodiblock copolymers underwent the same treatment.

${ }^{13} \mathrm{C}\left\{{ }^{1} \mathrm{H}\right\}$ NMR spectra of sPS and aPS- $b$-sPS copolymers were recorded on a AM-500 Bruker spectrometer operating at $125 \mathrm{MHz}$ at $313-353 \mathrm{~K}$ in $\mathrm{C}_{2} \mathrm{D}_{2} \mathrm{Cl}_{4}$. Molecular weights $\left(M_{\mathrm{n}}\right.$ and $\left.M_{\mathrm{w}}\right)$ and polydispersities $\left(M_{\mathrm{w}} / M_{\mathrm{n}}\right)$ of polymers were determined by high temperature gel permeation chromatography (GPC) using a Waters GPC-V2000 apparatus equipped with RI detector and a PL GEL mixed-B column, using a calibration vs. PS standards. Measurements were recorded at $150{ }^{\circ} \mathrm{C}$ at $1.0 \mathrm{~mL} \cdot \mathrm{min}^{-1}$ using as eluent 1,2,4-trichlorobenzene (TCB) stabilized with di-tert-butyl-methyl-4-phenol (BHT).

Differential scanning calorimetry (DSC) analyses were performed on a Setaram DSC 131 apparatus at a heating rate of $10{ }^{\circ} \mathrm{C} \cdot \mathrm{min}^{-1}$, under a continuous flow of helium, using aluminum capsules. For the non-isothermal crystallization experiments, the samples were cooled to room temperature at various rates $\left(5,10\right.$ and $20{ }^{\circ} \mathrm{C} \cdot \mathrm{min}^{-1}$ ). For isothermal crystallization experiments, the samples were quickly cooled down $\left(40{ }^{\circ} \mathrm{C} \cdot \mathrm{min}^{-1}\right)$ to various pre-set temperatures. The well-known Avrami equation [viii] was used to analyze the overall crystallization kinetics under isothermal conditions. In this macrokinetic model, the solid fraction as a function of time, $\mathrm{V}_{\mathrm{c}}(\mathrm{t})$, is related to the crystallization time $t$ according to:

$$
1-\mathrm{V}_{\mathrm{c}}=\exp \left(-\mathrm{K}(\mathrm{T}) \mathrm{t}^{\mathrm{n}}\right)
$$

which is usually transformed into the double-logarithmic form:

$$
\log \left(-\ln \left(1-\mathrm{V}_{\mathrm{c}}\right)\right)=\log \mathrm{K}(\mathrm{T})+n \log t
$$

where $\mathrm{V}_{\mathrm{c}}$ is the relative solid fraction at time $t, \mathrm{~K}(\mathrm{~T})$ is the crystallization rate constant for temperature T, $n$ is the Avrami exponent describing the crystal growth geometry and nucleation mechanism [ix]. The parameters $n$ and $\mathrm{K}(\mathrm{T})$ were calculated by plotting $\log \left(-\ln \left(1-\mathrm{V}_{\mathrm{c}}\right)\right)$ vs. $\log (t)$ and evaluating the slope and intercept of the best fitting line, respectively. 
Wide angle powder X-ray diffraction (WAXRD) analysis of sPS- $b$-aPS, aPS/sPS blends and aPS/sPS blends modified with sPS- $b$-aPS was performed in reflection geometry by using an automatic Bruker D8 Advance diffractometer with nickel-filtered CuKa radiation. Samples for WAXRD were prepared by the "solution mixture" procedure [4a] described above for the preparation of blends.

Monitoring of crystallization experiments by Polarized Optical Microscopy was performed with an optical microscope Leica DMRX through a $\times 20$ objective lens under light polarization. The different states of crystallization were recorded with a digital camera Leica DF 350. The camera was calibrated in a linear mode without overexposure of any pixel in 16 bit mode in order to apply quantitative analyses of images. The observation of crystallization was done in a Mettler FP82 hot-stage controlled by a Mettler FP8 unit. The temperature inside the hot-stage was calibrated with an indium sample $\left(T_{\mathrm{m}}=156.6^{\circ} \mathrm{C}\right)$ at different heating rates. The crystallization of the different PS samples was observed under a constant cooling-rate $\left(\mathrm{d} T / \mathrm{d} t=-10{ }^{\circ} \mathrm{C} \cdot \mathrm{min}^{-1}\right)$ and the temperature was corrected from the thermal lag, using the indium calibration. A time lapse of 6 seconds was applied on the digital camera to record the crystallization states with $1{ }^{\circ} \mathrm{C}$ intervals during cooling. The crystallization kinetics (Avrami) was measured by light depolarization using "Scion Image" software. Light intensity increased from none (molten polymer) to a maximum value, due to light depolarization by the crystalline phase inside the semi-crystalline polymer. The light depolarization intensity measurements were first normalized by the intensity measured at the end of crystallization. The normalized intensity was derived vs. time to define the conversion rate $\mathrm{d} \alpha / \mathrm{d} t=\mathrm{d}\left(\mathrm{I} / \mathrm{I}_{\infty}\right) / \mathrm{d} t$.

A very thin sample $(c a .10 \mu \mathrm{m})$ was used in order to have a linear dependence of light depolarization with the crystal content, i.e. conversion in the solid state. It was able to show the individual morphologies (spherulites for instance). Their size was deduced from a linescan intensity measurement along the diameter of the morphology using the software "Image J"; this delivered the depolarized intensity along the line-scan. For a spherulitic growth, the 
distance between two sharp interfaces, i.e. the spherulites and the melt, defines the diameter of the spherulites. The increase of the distance between these two interfaces $v s$. time, i.e. temperature, led to the growth rate as a function of temperature with the following law:

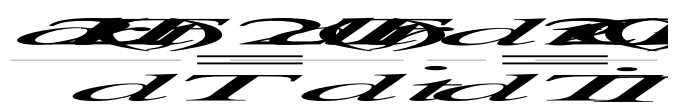

where the diameter $(2 r)$ measurement gave the crystalline growth-rate $(\mathbf{G})$ as a function of the cooling-rate $(\dot{T})$.

\section{Experimental Results and Discussion}

\subsection{DSC characterization}

Polymer samples with different molecular features were used (Table 1). Three sPS (namely, sPS-1, sPS-3 and sPS-2) samples were synthesized in our laboratory by using either the $\mathrm{Cp}^{*} \mathrm{TiBn}_{3} / \mathrm{B}\left(\mathrm{C}_{6} \mathrm{~F}_{5}\right)_{3} \quad[$ Erreur ! Signet non $\quad$ défini. $] \quad$ or $\left(\mathrm{Me}_{3} \mathrm{SiC}_{5} \mathrm{Me}_{4}\right) \mathrm{Sc}\left(\mathrm{CH}_{2} \mathrm{SiMe}_{3}\right)_{2}(\mathrm{THF}) /\left[\mathrm{Ph}_{3} \mathrm{C}\right]^{+}\left[\mathrm{B}\left(\mathrm{C}_{6} \mathrm{~F}_{5}\right)_{4}\right]^{-} \quad$ [Erreur ! Signet non défini.] catalytic systems.

Table 1. Molecular features of the sPS, aPS and sPS- $b$-aPS copolymer samples used.

\begin{tabular}{|c|c|c|c|c|}
\hline sample & sPS tacticity ${ }^{\mathrm{a}}$ & $\begin{array}{c}M_{\mathrm{n}} \\
{\left[\mathrm{g} \cdot \mathrm{mol}^{-1}\right]^{\mathrm{b}}}\end{array}$ & $\begin{array}{c}M_{\mathrm{w}} \\
{\left[\mathrm{g} \cdot \mathrm{mol}^{-1}\right]^{\mathrm{b}}}\end{array}$ & $M_{\mathrm{w}} / M_{\mathrm{n}}^{\mathrm{b}}$ \\
\hline sPS-1 ${ }^{\mathrm{c}}$ & $>99 \%[\mathrm{rrrrr}]$ & 53,000 & 106,000 & 2.0 \\
\hline sPS- $2^{\mathrm{d}}$ & $>99 \%[\mathrm{rrrrr}]$ & 201,000 & 322,000 & 1.6 \\
\hline $\mathrm{sPS}-3^{\mathrm{c}}$ & $>99 \%[\mathrm{rrrrr}]$ & 9,000 & 17,000 & 1.9 \\
\hline aPS-1 & $25 \%[r r]$ & 52,000 & 112,000 & 2.1 \\
\hline aPS-2 & $25 \%[r r]$ & 5,000 & 12,500 & 2.5 \\
\hline aPS-3 & $25 \%[r r]$ & 124,500 & 250,000 & 2.0 \\
\hline sPS- $b$-aPS Cop- 1 & $>99 \%[\mathrm{rrrrr}]$ & 33,000 & 74,800 & 2.3 \\
\hline sPS- $b$-aPS Cop- 2 & $>99 \%[\mathrm{rrrrr}]$ & 51,000 & 124,100 & 2.4 \\
\hline sPS- $b$-aPS Cop-3 & $>99 \%[\mathrm{rrrrr}]$ & 87,000 & 191400 & 2.2 \\
\hline
\end{tabular}


${ }^{\text {a }}$ Determined by ${ }^{13} \mathrm{C}\left\{{ }^{1} \mathrm{H}\right\}$ NMR spectroscopy at $125 \mathrm{MHz}$ in $\mathrm{C}_{2} \mathrm{D}_{2} \mathrm{Cl}_{4}$ at $80{ }^{\circ} \mathrm{C}$; ${ }^{\text {b }}$ Determined by GPC in 1,2,4-trichlorobenzene at $150{ }^{\circ} \mathrm{C} v s$. PS standards; ${ }^{\mathrm{c}}$ Prepared from a $\mathrm{Cp}{ }^{*} \mathrm{TiBn}_{3} / \mathrm{B}\left(\mathrm{C}_{6} \mathrm{~F}_{5}\right)_{3}$ catalyst [Erreur ! Signet non défini.]; ${ }^{\mathrm{d}}$ Prepared from a $\left(\mathrm{Me}_{3} \mathrm{SiC}_{5} \mathrm{Me}_{4}\right) \mathrm{Sc}\left(\mathrm{CH}_{2} \mathrm{SiMe}_{3}\right)_{2}(\mathrm{THF}) /\left[\mathrm{Ph}_{3} \mathrm{C}\right]^{+}\left[\mathrm{B}\left(\mathrm{C}_{6} \mathrm{~F}_{5}\right)_{4}\right]^{-}$catalyst [Erreur ! Signet non défini.].

Consistent with the tacticity determined by ${ }^{13} \mathrm{C}\left\{{ }^{1} \mathrm{H}\right\}$ NMR spectroscopy ([rrrrr $\left.]>99 \%\right)$, all three samples showed melting temperatures $\left(T_{\mathrm{m}}\right)$ and crystallization temperatures $\left(T_{\mathrm{c}}\right)$ typical of highly syndiotactic polystyrene [Erreur ! Signet non défini.]. DSC analyses by changing the cooling-rates (i.e., 5, 10 and $20{ }^{\circ} \mathrm{C} \cdot \mathrm{min}^{-1}$ ) were performed and, as usually observed, the $T_{\mathrm{c}}$ values increased by reducing the cooling-rate (see Table S1 in the supporting information). At each cooling-rate used, noticeable differences in the $T_{\mathrm{c}}$ values were observed for the three samples, with the following trend: sPS-3 $>$ sPS-1 $>$ sPS-2, suggesting that the crystallization kinetics of sPS decreases with the molecular weight $[\mathrm{x}]$. Confirmation of the latter observation came from isothermal crystallization studies (see Figures S1 and S2). The crystallization rate constants $\mathrm{K}(\mathrm{T})$ were determined at $244{ }^{\circ} \mathrm{C}$, with sPS-3 $\left(\mathrm{K}_{244}=31.2 \mathrm{~min}^{-n}\right)$ and sPS-1 $\left(\mathrm{K}_{244}=11.5 \mathrm{~min}^{-n}\right)$ crystallizing $c a .20$ and 10 times, respectively, faster than sPS$2\left(\mathrm{~K}_{244}=1.4 \mathrm{~min}^{-n}\right)$. The values of the Avrami exponent (sPS-3, $n=3.2$; sPS-1, $n=3.0$, and sPS-2, $n=2.5$ ) were consistent with a three-dimensional spherulitic growth from an instantaneous nucleation [xi].

Table 2. Component and compositions for sPS-b-aPS copolymers, sPS/aPS blends and sPS/aPS blends modified with $15 \%$ of sPS- $b$-aPS

\begin{tabular}{lcccc}
\hline Sample & Component & $\begin{array}{c}M_{\mathrm{n}} \\
\left(\times 10^{3} \mathrm{~g}^{\left.-\mathrm{mol}^{-1}\right)}\right.\end{array}$ & $\begin{array}{c}\text { Composition } \\
(\text { wt } \%)\end{array}$ & $\begin{array}{c}\text { aPS } \\
(\text { wt } \%)\end{array}$ \\
\hline sPS-1 & sPS-1 & 53 & 100 & 0 \\
Blend-1 & sPS-1/aPS-1 & $53 / 52$ & 75 & 25 \\
Blend-2 & sPS-1/aPS-1 & $53 / 52$ & 50 & 50 \\
Blend-3 & sPS-1/aPS-1 & $53 / 52$ & 25 & 75 \\
Blend-4 & sPS-1/aPS-1 & $53 / 52$ & 20 & 80 \\
Blend-5 & sPS-1/aPS-1 & $53 / 52$ & 15 & 85 \\
Blend-6 & sPS-1/aPS-1 & $53 / 52$ & 10 & 90
\end{tabular}




$\begin{array}{lcccc}\text { Blend-7 } & \text { sPS-1/aPS-2 } & 53 / 5 & 50 & 50 \\ \text { Blend-8 } & \text { sPS-1/aPS-3 } & 53 / 125 & 50 & 50 \\ & & & & 50 \\ \text { Blend-9 } & \text { sPS-3/aPS-1 } & 9 / 52 & 50 & 50 \\ \text { Blend-10 } & \text { sPS-2/aPS-1 } & 201 / 52 & 50 & 51 \\ & & & & 77 \\ \text { Blend-2-mod }^{*} & \text { sPS-1/aPS-1/Cop-1 } & 53 / 52 / 33 & 49 & 85 \\ \text { Blend-4-mod* }^{*} & \text { sPS-1/aPS-1/Cop-1 } & 53 / 52 / 33 & 23 & 55 \\ \text { Blend-6-mod } & \text { sPS-1/aPS-1/Cop-1 } & 53 / 52 / 33 & 15 & 79 \\ & & & & 88 \\ \text { Cop-1 } & \text { sPS- } b \text {-aPS } & 33 & 45 & 21 \\ \text { Cop-2 } & \text { sPS- } b \text {-aPS } & 51 & 12 & \\ \text { Cop-3 } & \text { sPS- } b \text {-aPS } & 87 & \end{array}$

(*) composition was calculated by taking into account the $15 \%$ of sPS-b-aPS copolymer and its composition

The thermal properties investigations were extended to sPS/aPS blends. Initially, several blends with different sPS/aPS ratio, keeping constant the molecular weight of both components, were prepared following a literature "solution mixing" procedure [Erreur ! Signet non défini.a], using sPS-1 $\left(M_{\mathrm{n}}=53,000 \mathrm{~g} \cdot \mathrm{mol}^{-1}\right)$ and aPS-1 $\left(M_{\mathrm{n}}=52,000 \mathrm{~g} \cdot \mathrm{mol}^{-1}\right)$ (Table 2). All blends were characterized under non-isothermal conditions and the results were compared with those of the corresponding pure sPS (Table S2). Both melting and crystallization enthalpies varied with the composition of the blends, showing an almost linear relationship with the sPS fraction, i.e. a mixing rule (Figure S3). On the other hand, for almost all samples, the enthalpy values normalized for sPS content showed no dependence on composition. Exception to this trend was observed for Blend-4 and -5 with content of sPS up to $20 \%$ at high crystallization cooling-rate $\left(20^{\circ} \mathrm{C} \cdot \mathrm{min}^{-1}\right)$ and for Blend- 6 at any crystallization cooling rate (Table 3). Indeed, no crystallization peak was observed for this blend; this is accounted for by the diluent effect of aPS on crystallization of sPS [2].

For all the blends studied, only one $T_{\mathrm{g}}$ was observed. Yet, because sPS and aPS feature essentially the same $T_{\mathrm{g}}$, the latter observation cannot be used as a clear-cut indicator of sPS and aPS chains miscibility over the entire composition range studied, although this has been independently reported [Erreur ! Signet non défini.c]. 
In order to evaluate the possible influence of the molecular weight on the thermal properties, two additional sets of 50:50 aPS/sPS blends were prepared by keeping constant the molecular weight of the sPS component in the first case and that of aPS in the second one (Blends-2, $-7,-8$ and Blends-2, $-9,-10$, Table 2, respectively). It is worth mentioning that the effect of the molecular weight of sPS in sPS/aPS blends has been never explored as far as we know. The effect of the decrease of the molecular weight on the thermal properties was opposite for the two components. First, the lower the molecular weight of aPS, the slower the crystallization and the lower the $T_{\mathrm{m}}$. This observation is in agreement with the literature reported for aPS/sPS blends of similar composition (50:50 aPS/sPS) [Erreur ! Signet non défini.]. On the contrary, decrease of the molecular weight of the sPS component resulted in faster crystallization, following the same trend than that observed for the corresponding homopolymers (Figure 1, Tables S3 and S4).

Table 3. Thermal properties of sPS- $b$-aPS block copolymers, aPS/sPS blends, and aPS/sPS blends modified with $15 \%$ of sPS- $b$-aPS block copolymers of similar composition (raw enthalpy values and, in brackets, enthalpy values normalized for sPS content)

\begin{tabular}{|c|c|c|c|c|c|c|c|c|c|}
\hline $\begin{array}{l}\text { Heating and } \\
\text { cooling rate }\end{array}$ & \multicolumn{2}{|c|}{$+10^{\circ} \mathrm{C} \cdot \mathrm{min}^{-1}$} & \multicolumn{2}{|c|}{$-5^{\circ} \mathrm{C} \cdot \mathrm{min}^{-1}$} & \multicolumn{2}{|c|}{$-10^{\circ} \mathrm{C} \cdot \mathrm{min}^{-1}$} & \multicolumn{2}{|c|}{$-20{ }^{\circ} \mathrm{C} \cdot \mathrm{min}^{-1}$} & \multirow[b]{2}{*}{$\begin{array}{c}T_{\mathrm{g}} \\
{\left[{ }^{\circ} \mathrm{C}\right]}\end{array}$} \\
\hline Sample & $\begin{array}{c}T_{\mathrm{m}} \\
{\left[{ }^{\circ} \mathrm{C}\right]} \\
\end{array}$ & $\begin{array}{c}\Delta \mathrm{H}_{\mathrm{m}} \\
{\left[\mathrm{J} \cdot \mathrm{g}^{-1}\right]}\end{array}$ & $\begin{array}{c}T_{\mathrm{c}} \\
{\left[{ }^{\circ} \mathrm{C}\right]}\end{array}$ & $\begin{array}{c}\Delta \mathrm{H}_{\mathrm{c}} \\
{\left[\mathrm{J} . \mathrm{g}^{-1}\right]}\end{array}$ & $\begin{array}{c}T_{\mathrm{c}} \\
{\left[{ }^{\circ} \mathrm{C}\right]}\end{array}$ & $\begin{array}{c}\Delta \mathrm{H}_{\mathrm{c}} \\
{\left[{\left.\mathrm{J} . \mathrm{g}^{-1}\right]}^{-1}\right.}\end{array}$ & $\begin{array}{c}T_{\mathrm{c}} \\
{\left[{ }^{\circ} \mathrm{C}\right]}\end{array}$ & $\begin{array}{c}\Delta \mathrm{H}_{\mathrm{c}} \\
{\left[{\left.\mathrm{J} . \mathrm{g}^{-1}\right]}^{-1}\right]}\end{array}$ & \\
\hline sPS-1 & 271.9 & 13.3 & 245.9 & -12.9 & 241.2 & -12.4 & 234.8 & -12.8 & 104.5 \\
\hline Blend-2 & 269.9 & $7.5(15.0)$ & 239.2 & $-7.4(-14.8)$ & 234.1 & $-7.6(-15.2)$ & 225.8 & $-8.0(-16.0)$ & 102.5 \\
\hline Blend-2-mod & 270.4 & $8.7(17.7)$ & 241.1 & $-7.1(-14.8)$ & 235.4 & $-7.1(-14.8)$ & 228.1 & $-6.8(-13.8)$ & 107.7 \\
\hline Cop-1 & 269.1 & $8.1(17.9)$ & 242.6 & $-6.3(-14.0)$ & 238.2 & $-6.5(-14.4)$ & 233.5 & $-7.9(-17.5)$ & 106.1 \\
\hline Blend-4 & 270.1 & $3.2(16.0)$ & 233.4 & $-2.9(-14.5)$ & 223.5 & $-2.6(-13.0)$ & 212.6 & $-1.1(-5.5)$ & 105.5 \\
\hline Blend-4-mod & 270.9 & $4.8(20.8)$ & 236.0 & $-4.7(-20.4)$ & 229.2 & $-3.7(-16.1)$ & 224.8 & $-4.3(-18.7)$ & 107.3 \\
\hline Cop-2 & 268.8 & $2.3(11.0)$ & 237.7 & $-2.7(-12.9)$ & 231.8 & $-2.9(-13.8)$ & 223.4 & $-2.8(-13.3)$ & 104.3 \\
\hline Blend-5 & 269.5 & $2.3(15.3)$ & 229.8 & $-2.2(-14.7)$ & 212.6 & $-2.1(-14.0)$ & 200.0 & $-0.3(-2.0)$ & 106.0 \\
\hline Blend-6 & 269.4 & $0.34(3.4)$ & n.o. & n.o. & n.o. & n.o. & n.o. & n.o. & 101.0 \\
\hline Blend-6-mod & 270.0 & $2.5(16.5)$ & 235.2 & $-2.8(-18.6)$ & 228.3 & $-1.9(-12.6)$ & 213.4 & $-1.9(-12.6)$ & 104.9 \\
\hline
\end{tabular}


(insert Figure 1 here)

Our preliminary studies on the thermal characterization of the new sPS- $b$-aPS stereodiblock copolymers indicated that, in general, these materials showed a similar behavior to that of the corresponding sPS/aPS blends [Erreur ! Signet non défini.]. In particular, the linear dependence of the melting and crystallization enthalpies with the sPS fraction in the copolymers was noted (see above comment for virtually constant normalized enthalpy values. Interestingly enough yet, in the whole range of compositions studied (sPS/aPS: 90:10 to 10:90), those stereodiblock copolymers were found to crystallize systematically faster than the corresponding aPS/sPS blends. This effect was found to be amplified at high cooling-rate and proved more significant for the stereodiblock polymers with a higher aPS content (8090\%) (Figure 2 and Table 3).

For instance, Cop-1 crystallized faster than Blend-2; both materials had a similar (ca. 50:50) aPS/sPS composition but different molecular weight for the sPS block (i.e., $M_{\mathrm{n}} \sim$ $14,000 \mathrm{~g} \cdot \mathrm{mol}^{-1}$ for the diblock vs. $53,000 \mathrm{~g} \cdot \mathrm{mol}^{-1}$ for the blend). Since crystallization is a molecular weight-dependent phenomenon and the lower the molecular weight of sPS, the faster the crystallization (vide supra), this difference in molecular weight could account for the observed faster crystallization for the copolymer. However, it is important to mention that Cop-1 was also found to crystallize faster than Blend-8 (Tables 3 and S3), which showed not only similar composition ( $c$. 50:50 aPS/sPS) but also lower molecular weight for the sPS component $\left(M_{\mathrm{n}} \sim 9,000 \mathrm{~g} \cdot \mathrm{mol}^{-1}\right)$.

(insert Figure 2 here)

In view of the above results, to assess a possible effect of such sPS- $b$-aPS stereodiblock copolymers on the crystallization behavior of blends, new aPS/sPS blends with 
different compositions (aPS/sPS $=c a .50: 50,80: 20$ and 90:10) and modified by adding 15\% of stereodiblock copolymer Cop-1 (aPS/sPS =ca. 55:45) were prepared (Table 3). Addition of the stereodiblock copolymer in the blends affected neither the glass transition temperature nor the melting temperature, which remained essentially similar to that of the unmodified blends, but interestingly affected the crystallization behavior of the blends, driving a faster crystallization as compared to that of the unmodified ones. This effect was amplified in the blends with a higher aPS content (i.e., blends with $90 \%$ of aPS) and by a high cooling-rate (Table 3, Figure 3). These kinetic effects are similar to those observed on Cop-1, which seems to drive the crystallization kinetics of modified blends.

In summary, these crystallization studies under non-isothermal conditions of highly syndiotactic homopolystyrene (sPS), new sPS- $b$-aPS stereodiblock copolymers, blends made of aPS and sPS, and aPS/sPS blends modified with sPS- $b$-aPS copolymers indicated that, at a given aPS/sPS ratio, the trend in crystallization is: sPS homopolymers $>$ sPS- $b$-aPS copolymers $\sim$ sPS/aPS blends modified with sPS- $b$-aPS copolymers $>$ sPS/aPS blends.

\section{(insert Figure 3 here)}

To better understand the crystallization behavior and to precise the crystallization parameters of these materials, pure sPS, blends, stereodiblock copolymers and blends modified by the block copolymer Cop-1 of similar composition ( $c a$. 50:50 aPS/sPS) were studied under isothermal conditions. After holding in a melt state for $5 \mathrm{~min}$, the samples were crystallized at various pre-set temperatures. The crystallization peak time $\left(t_{p}\right)$ was defined as the time at which the maximum DDSC signal is observed and its reciprocal value $\left(\mathrm{t}_{\mathrm{p}}^{-1}\right)$ is recognized to be proportional to the overall crystallization rate [Erreur ! Signet non défini.a]. Figure 4 plots values of $\mathrm{t}_{\mathrm{p}}^{-1}$ vs. $T_{\mathrm{c}}$ for pure sPS, its blends (regular and modified one) and stereodiblock copolymers (sPS-1, Blend-2, Blend-2-mod and Cop-1, respectively; Table 2). The plot confirmed the aforementioned trend in crystallization observed under nonisothermal conditions: at a given $T_{\mathrm{c}}$, pure sPS crystallizes the fastest (largest value of $\mathrm{t}_{\mathrm{p}}^{-1}$ ), 
followed by the stereodiblock copolymer and modified blend (both showing similar values of $\mathrm{t}_{\mathrm{p}}^{-1}$ ), and finally the regular aPS/sPS blend (lowest value of $\mathrm{t}_{\mathrm{p}}^{-1}$ ). For all of these samples, the Avrami exponent $n$, which provides an information on the nature of the nucleation mechanism and crystal growth geometry, were found in the range $n=2.4-3.0$, consistent with a threedimensional spherulitic growth from an instantaneous nucleation (Figure 5) [Erreur ! Signet non défini.]. The crystallization rate constants $\mathrm{K}$, obtained by using the Avrami macrokinetic model at $244{ }^{\circ} \mathrm{C}$, were $11.5,2.0,1.9$, and $0.18 \mathrm{~min}^{-\mathrm{n}}$ for sPS, the copolymer, the modified blend and the blend, respectively.

(insert Figure 4 here)

(insert Figure 5 here)

Table 4. Avrami exponent ( $n$ ) and crystallization rate constant $(\mathrm{K})$ determined by isothermal DSC studies for a pristine sPS (sPS-1), a regular aPS/sPS blend (Blend-2, Table 2), a aPS- $b$ sPS stereodiblock copolymer (Cop-1, Table 1), and a aPS/sPS blend modified with $15 \%$ of a sPS- $b$-aPS copolymer (Blend-2-mod, Table 2)

\begin{tabular}{lcc}
\hline \multicolumn{1}{c}{ sample } & $n$ & $\begin{array}{c}\mathrm{K} \\
\left(\mathrm{min}^{-\mathrm{n}}\right)\end{array}$ \\
\hline sPS-1 & 3.0 & 11.5 \\
Cop-1 & 2.8 & 2.00 \\
Blend-2-mod & 3.0 & 1.90 \\
Blend-2 & 2.4 & 0.18 \\
\hline
\end{tabular}

In general, for semi-crystalline polymers and for sPS in particular, crystallization from the melt strongly depends on the experimental conditions, e.g. the maximum temperature ( $\left.T_{\max }\right)$ at which the sample is heated, the permanence time of the melt at that temperature $\left(t_{\max }\right)$, the cooling-rate, and on the crystalline form of the starting material [xii]. In order to erase the thermal history (that is, destroy all crystalline seeds), some experiments were 
performed on the stereodiblock copolymers, blends and modified blends by holding the samples for $5 \mathrm{~min}$. at a $T_{\max }$ of $335^{\circ} \mathrm{C}$ before changing the cooling-rates $(-5,-10$, and -20 ${ }^{\circ} \mathrm{C} \cdot \mathrm{min}^{-1}$ ). For the aPS- $b$-sPS block copolymers, these experiments gave results quite similar to those obtained with a $T_{\max }$ of $300{ }^{\circ} \mathrm{C}$ (decrease of $T_{\mathrm{c}}$ values by $2-3{ }^{\circ} \mathrm{C}$ ). On the other hand, quite different results were obtained for the aPS/sPS blends for which the $T_{\mathrm{c}}$ values dropped by about $10-12^{\circ} \mathrm{C}$. The modified blends instead showed intermediate results with a decrease of the $T_{\mathrm{c}}$ values of $c a .8^{\circ} \mathrm{C}$ (Figure 6 and Table S5).

(insert Figure 6 here)

\subsection{Polymorphism: WAXRD characterization}

sPS presents a very complex polymorphic behavior [Erreur ! Signet non défini.a,xiii]: Two crystalline forms containing planar zigzag chains ( $\alpha$ [xiv] and $\beta[\mathrm{xv}]$ ), three crystalline forms containing s(2/1)2 helical chains ( $\gamma$ [Erreur ! Signet non défini.,xvi], $\delta$ [xvii], and $\varepsilon$ [xviii]), and two mesomorphic forms presenting trans-planar [xix] or helical [xx] chains have been obtained and characterized. It is worth noting that $\delta$ and $\varepsilon$ crystalline phases are "nanoporous", i.e. crystalline phases with empty space available for sorption of suitable low-molecular-mass guest molecules leading to the formation of co-crystalline phases ( $\delta$-clathrates [xxi], $\varepsilon$-clathrates [xxii] and intercalates [xxiii]). Both crystalline forms $\alpha$ and $\beta$ can be obtained from the melt and the preferential crystallization of one of the two strongly depends on the experimental conditions and on the crystalline forms of the starting materials. Starting from different crystalline forms, under given experimental conditions, a sPS sample can crystallize faster than another one if in the melt state some crystals of the $\alpha$ polymorphic form are present (self-nucleation) [Erreur ! Signet non défini.,Erreur ! Signet non défini.a].

The copolymers and blends of the present study were therefore characterized by Wide Angle X-Ray powder Diffraction (WAXRD) analysis. The samples were prepared according 
the "solution mixing method" [4a]. Figures 7 and 8 show the X-ray diffraction patterns of sPS- $b$-aPS copolymers, aPS/sPS blends and aPS/sPS blends modified with sPS- $b$-aPS copolymers of similar composition (50:50 and 10:90, respectively; see Tables 1 and 2). All the stereodiblock copolymers, even that which contained only $10 \%$ of sPS (Cop3), showed a X-ray diffraction pattern typical of the $\beta$ form, as indicated by the presence of intense reflections at $2 \vartheta=6.15$ and $12.35^{\circ}$ [Erreur ! Signet non défini.]. The same reflections, albeit of much lower intensity, were observed for blend 2 (50:50 aPS/sPS), and even for blend 6 that contained only $10 \%$ of sPS although the sample is prevailingly amorphous. Interestingly, the X-ray diffraction patterns of the aPS/sPS blends modified by stereodiblock copolymers showed reflections corresponding to the $\beta$ form and the intensity of those reflections was more intense than that observed for the regular blends, suggesting higher crystallinity of sPS in the former case. It is also worth noting that, upon addition of sPS-b-aPS, the amorphous 90:10 aPS/sPS blend became partially crystalline; this observation is consistent with the DSC analyses that showed the appearance of a crystallization peak upon similar modification (vide supra, Figure 3). All of these polymers crystallize in the same crystalline phase and the difference in the crystallization kinetics must be searched in a difference on the nuclei density and/or on the crystalline growth-rate.

(insert Figure 7 here)

(insert Figure 8 here)

\subsection{Characterization via Polarized Optical Microscopy (POM)}

Crystallization is known to depend on three main parameters: the nucleation density and rate, the thermal dependence of the growth-rate, and the geometry of growth (eq. 1). Polarized Optical Microscopy (POM) is a usual technique that allows to access and evaluate those individual parameters. In an attempt to clarify the results of the above DSC studies, we have studied by this technique, under the same crystallization conditions, a series of selected 
blends, block copolymers, and blends modified by block copolymers. The same experimental pictures were used to study pristine homopolystyrene sPS-1 (used as a reference), Blend-2 and Blend-4, block copolymers Cop-1 and -2 , and a aPS/sPS blend modified by a block copolymer (Blend-2-mod and Blend-4-mod). The overall methodology and experimental procedures used are described in details in the Supporting Information. As a general remark, these optical studies confirmed the main conclusions of non-isothermal and isothermal crystallization studies.

Figure 9 shows, for each sample, the profile of the overall crystallization obtained by deriving the light intensity measurements $v s$. time as a function of temperature. The highest crystallization temperature within the sharpest temperature range was observed for pristine sPS, while the other samples showed wider crystallization-temperature ranges shifted to lower crystallization temperatures. Anyway, the crystallization temperatures deduced from DSC (Table 3) and POM (Figure 9) at a constant cooling-rate $\left(\mathrm{d} T / \mathrm{d} t=-10^{\circ} \mathrm{C} \cdot \mathrm{min}^{-1}\right)$ were quite similar, with a $3{ }^{\circ} \mathrm{C}$ maximum deviation for sPS-1 and Blend-2-mod. The quantitative analysis of morphologies, nucleation density and crystalline growth-rate are representative of all the experimental apparatus (DSC, optical microscopy) and thermal conditions (isothermal and constant cooling-rate).

(insert Figure 9 here)

Figure 9. Conversion-rate deduced from light intensity variation measured by POM (conducted at constant cooling-rate $\mathrm{d} T / \mathrm{dt}=-10{ }^{\circ} \mathrm{C} \cdot \mathrm{min}^{-1}$ ) for homopolymer sPS-1, block copolymers Cop-1 and Cop-2, sPS-aPS Blend-2 and Blend-4, and a sPS-aPS blend modified by a sPS- $b$-aPS stereodiblock copolymer (Blend-2-mod).

The optical micrographs obtained for sPS, stereoblock copolymer (Cop-2, aPS/sPS = ca. 80:20) and the corresponding blend and blend modified (Blend-4 and Blend-4-mod respectively) at almost the same crystallization conversion $\left(\mathrm{I} / \mathrm{I}_{\infty}=\alpha=0.1\right)$, and thus at 
different temperatures, are reported in Figure 10 (see Figure S9 for other samples). Different morphologies were observed in the early stages of crystallization according to the nature (homopolymer, copolymer, blend, modified blend) and the composition (aPS/sPS ratio) of the sample. Pristine homopolymer sPS-1 showed a mixing of spherulites with initially elongated species, growing later in spherulites (Figure 10a and Figure S9), while for both block copolymers Cop-2 and Cop-1, as well as for Blend-2 and Blend-2-mod, a spherulitic organization was observed from the early stages (Figure 10b and Figure S9, respectively). Interestingly, Blend-4 and Blend-4-mod showed more complex organization (Figures 10c and 10d).

\section{(insert Figure 10 here)}

To explain the origin of these differences, the geometry of crystalline growth and the crystalline growth-rate was studied as a function of temperature using the method applied for all the polymers which crystallize with an interfacial process, i.e. a sharp intensity profile at the boundaries of a morphology. The crystalline growth-rate was deduced from the size evolution of a single morphology, which was measured by the light intensity profile along the spherulite diameter or the principal direction of other morphologies.

Blend-2 and Blend-4 were chosen as representative of the two different morphologies observed above, and Figures 11 and 12 show the respective crystalline growths. For Blend-2 $($ aPS/sPS $=c a .50: 50)$, a progressive increase of the maximum light intensity from $240.5^{\circ} \mathrm{C}$ to $237.5{ }^{\circ} \mathrm{C}$ was observed, due to both the increase of the size and the thickness of the morphology (Figure 11). At $236.5{ }^{\circ} \mathrm{C}$, the light intensity reached a limit value, which is accounted for by a limit of the thickness of the morphology imposed by the two glasses of the thin sample. Therefore, from this temperature, only the spherulites diameter increased progressively during the cooling, allowing to determine the corresponding crystalline growthrate (vide infra). The observed behavior can be described by regular nucleation and crystalline growth mechanisms controlled by an interfacial process. 
On the contrary, Blend-4 (aPS/sPS $=c a .80: 20)$ showed a different time evolution of the intensity profile. The light intensity increased as the function of temperature, indicative of crystallization event, with an almost Gaussian profile, and the size of the grain morphology remained almost constant during the overall crystallization (Figure 12). This evolution does not correspond to a regular nucleation and crystalline growth mechanism and it can be explained by a spinodal decomposition. According to the theory [Erreur ! Signet non défini.c,xxiv], in the spinodal decomposition there is a fluctuation of concentrations followed by a local enrichment of one of the species (aPS, sPS); this transformation is mainly controlled by diffusion of molecular species with the crystallization process acting as the driving force; as a consequence, there is no change in the size of the domains (Figure 12). This model implies that aPS and sPS miscibility decreases at lower temperature, favored by the crystallization process. Such a phase separation with spinodal decomposition as an effect of the chain tacticity in polystyrene was previously observed only during cold crystallization at higher sPS content, i.e. in 50:50 blends [Erreur ! Signet non défini.c] and, more surprisingly, in pristine sPS as well [xxv].

(insert Figure 11 here)

(insert Figure 12 here)

Thus, Blend-2 and Blend-4, which differ only by their relative aPS/sPS composition, as well as the corresponding blends modified with block copolymers, showed two different crystallization mechanisms: a regular nucleation/growth and a phase separation due to spinodal decomposition. We assume that the high atactic PS fraction favors this spinodal decomposition, a phenomenon which has not been studied thus far to our knowledge. In sharp contrast, both stereodiblock copolymers, independently from their aPS/sPS composition, showed the same crystalline growth controlled by an interfacial process (vide infra). 
For all the samples that showed a spherulitic morphology (i.e., sPS-1, Cop-1, Cop-2, Blend-2, Blend-2-mod) [xxvi], the thermal evolution of the crystalline growth-rate was determined and compared with previous literature data obtained on sPS [Erreur ! Signet non défini.] (Figure 13). The measured growth-rates of sPS-1 and of Blend-2 were the same and are almost identical to data published by Takebe and Yamasaki for pristine sPS [Erreur ! Signet non défini.]. This strict identity was obviously expected for sPS homopolymers, since the growth-rate depends on regularity of the crystal structure, but it was more surprising for Blend-2 as the latter contains $50 \%$ of aPS. The growth-rate of Cop-1 and Blend-2-mod appeared, respectively, $18 \%$ and $48 \%$ greater than for sPS-1. The former difference of $18 \%$ observed for Cop- 1 falls within the range of experimental accuracy while the $48 \%$ difference for Blend-2-mod is more significant. Yet, the most significant result is the strong decrease of the crystalline growth-rate of Cop-2 as compared to all the other polystyrenes. For instance, at $238{ }^{\circ} \mathrm{C}$, the crystalline growth-rate of Cop- 2 is only $32 \%$ of that of sPS- 1 and Blend- 2 . Thus, a aPS/sPS blend (Blend-2) and a block copolymer (Cop-1) with up to ca. 50\% aPS do not affect significantly the crystalline growth-rate of pristine sPS, but a higher (i.e., 80\%) aPS content in a block copolymer (Cop-2) does strongly decrease the growth-rate of sPS.

(insert Figure 13 here)

Some polymers crystallize in a different temperature range while their growth-rate are almost the same. The nucleation density and its thermal evolution were evaluated to check this disagreement. The number of spherulites, determined from the optical observations as a function of temperature, was almost constant for all the polymers during a given crystallization experiment [xxvii]. This observation is consistent with an instantaneous nucleation, i.e. an Avrami exponent $n \sim 3$ (Table 4), and explains why all the spherulites have almost the same size at a given crystallization conversion (e.g. Figure $10 ; \alpha=0.1)$. It is possible to reduce the analysis of nucleation to the density of activated nuclei and the temperature of nucleation deduced from growth-rate measurement to radius $=0$ (Table 5). 
The nucleation density of sPS-1 was 14 times higher than that observed in Blend-2 and crystallites in the former case were observed at a temperature $8{ }^{\circ} \mathrm{C}$ higher. These two effects explain the difference in the crystallization temperature (Table 3). Interestingly, block copolymer Cop-1, which has almost the same aPS/sPS composition than Blend-2, showed a nucleation density ca. 5 times higher and a maximum nucleation temperature $5{ }^{\circ} \mathrm{C}$ higher than the latter blend. The modification of Blend-2 by incorporation of Cop-1 increased the nuclei density by a factor of $c a .2$ [xxviii] and the maximum temperature by $5{ }^{\circ} \mathrm{C}$. All the nuclei in Blend-2-mod seemed to be activated at the same time, resulting in an instantaneous nucleation; there is no separate nucleation of the blend components and the block copolymer Cop-1, which seems to co-crystallize with the sPS inside the aPS/sPS polymer blend.

Table 5. Observed nucleation density and the maximum temperature where the nuclei could be detected.

\begin{tabular}{|c|c|c|}
\hline Sample & density of nuclei $\left(\text { nuclei. } \mathrm{mm}^{-3}\right)^{\mathrm{a}}$ & Nucleation temperature $\left({ }^{\circ} \mathrm{C}\right)$ \\
\hline sPS-1 & 430,000 & 248 \\
Cop-1 & 160,000 & 245 \\
Cop-2 & 190,000 & 242 \\
Blend-2 & 30,000 & 240 \\
Blend-2-mod & 60,000 & 245 \\
\hline
\end{tabular}

${ }^{\text {a }}$ The accuracy of the density of nuclei is estimated to $\pm 20 \%$.

\section{General Discussion}

Different techniques, namely DSC, WAXRD and POM, have been used to investigate the melting behavior and the crystallization kinetics of sPS in pure sPS homopolymers, in aPS/sPS blends, in new sPS- $b$-aPS stereodiblock copolymers, and in sPS/aPS blends modified with these stereodiblock copolymers. A systematic analysis and comparison between copolymers and blends with the same components in a so wide composition range is 
unprecedented in the literature and constitutes the main originality of this paper. Several aspects emerged from the present studies. Crystallization studies by DSC performed under both non-isothermal and isothermal conditions led to coherent results and provided a clear crystallization trend: sPS homopolymers $>$ sPS- $b$-aPS copolymers $\sim$ sPS/aPS blends modified with sPS- $b$-aPS copolymers $>$ sPS/aPS blends. The influence of the molecular weight of both components in $c a$. 50:50 blends has been also evaluated. Opposite effects were observed for aPS and sPS: the lower the molecular weight of aPS, the slower the crystallization; on the other hand, the lower the molecular weight of sPS, the faster the crystallization.

Consistent with the existing literature [Erreur ! Signet non défini.], thermal studies of the aPS/sPS blends confirmed, by the observation of a single $T_{\mathrm{g}}$ and with enthalpy relaxation measurements, the miscibility of both components in the solid-state (aPS with amorphous phase of sPS [Erreur ! Signet non défini.d,xxix]) and the diluent effect of aPS. Blends with $c a$. 50:50 aPS/sPS compositions crystallized via a regular nucleation and crystalline growth mechanism controlled by an interfacial process. POM observations revealed, in these cases, spherulitic crystallization. On the other hand, blends containing only ca. $20 \%$ of sPS showed spinodal decomposition leading to local crystalline-rich domains (sPS) separated by aPS-rich domains. Interestingly, for the stereodiblock copolymers, independently from their composition, the POM studies showed always the same spherulitic mechanism of crystallization controlled by an interfacial process; the aPS and the amorphous phase of sPS are included inside the spherulites between the crystalline lamellae [Erreur ! Signet non défini.a]. The incorporation of aPS was found more in interfibrillar position than in interlamellar position, with an elongated shape and not as nodules [Erreur ! Signet non défini.a]. On the contrary, the blends modified with block copolymers showed the same crystallization mechanism of the corresponding unmodified one (Blend-2/Blend-2-mod and Blend-4/Blend-4-mod, respectively). Anyway, these POM studies confirmed the general the 
crystallization trend observed with DSC analysis, that is sPS $>$ sPS- $b$-aPS $\sim$ blends modified with sPS- $b$-aPS $>$ sPS/aPS blends.

Experiments aimed at clarifying the reasons of the observed faster crystallization of the stereodiblock copolymers have been performed. Two main aspects have been considered: (i) homogeneous nucleation $[\mathrm{xxx}]$ due to either lower molecular weights or presence of different polymorphic forms of the sPS component in the copolymers and in the blends; (ii) heterogeneous nucleation due to the presence of impurities (e.g., from catalyst residues) still present in the copolymers which act as nucleating agents.

Experimental evidences allowed to rule out homogeneous nucleation $(i)$ as the origin of faster crystallization; in fact, aPS- $b$-sPS copolymers with a sPS block of 14,000 g.mol ${ }^{-1}$ crystallized always faster than aPS/sPS blends with a similar composition, independently from the molecular weight of the sPS used in those blends $\left(M_{\mathrm{n}}=9,000-201,000 \mathrm{~g} \cdot \mathrm{mol}^{-1}\right)$. On the other hand, the WAXRD analyses revealed that in all the samples (sPS-b-aPS diblock copolymer, aPS/sPS blends and aPS/sPS blends modified with sPS- $b$-aPS) sPS adopts always the same $\beta$ polymorphic form. The presence of the same crystalline form for the sPS component in this variety of materials most likely arises from the treatments that all the materials underwent before thermal analysis. Indeed, casting from 1,2,4-trichlorobenzene at $200{ }^{\circ} \mathrm{C}$ and the long annealing in vacuum at $150{ }^{\circ} \mathrm{C}$ are known to lead to the observed polymorphic form $(\beta)$ [Erreur ! Signet non défini.]. According to the literature, if the starting sPS material is in the $\beta$ form, the melt crystallized samples are always in the $\beta$ form [Erreur ! Signet non défini.a]. This indicates that polymorphism of sPS cannot be at the origin of the observed different crystallization behavior.

Different response for blends and blends modified by copolymers were obtained by changing $T_{\max }$ from 300 to $335^{\circ} \mathrm{C}$. This effect can be accounted for by a higher homogeneity of the blends from higher $T_{\max }$ temperatures: from these more homogeneous samples, the spinodal decomposition, for Blend-4 and Blend-4-mod, should appear at a lower 
crystallization temperature (Figure 6 and Table S5) as observed, while the $T_{\mathrm{c}}$ values of the copolymers were only slightly affected by changing $T_{\max }$.

On the other hand, one could argue that the faster crystallization observed for the block copolymers, as compared to blends and blends modified by block copolymers, could arise, despite the careful purification of these materials (see Materials and Methods), from the possible presence in the copolymers of very low levels of impurities that would act as nucleating agents [xxxi,xxxii,xxxiii]. It is here noteworthy to remember that the density of nuclei in block copolymers $\left(160,000-190,000\right.$ nuclei.mm $\left.{ }^{-3}\right)$ was always higher than that in blends and modified blends $\left(30,000-60,000\right.$ nuclei.mm $\left.{ }^{-3}\right)$, even for quite different sPS/aPS ratio (Table 5). According to the classical homogeneous nucleation theory, the nuclei are activated with a strong nucleation-rate increase from high to low crystallization temperature. Thus, it is possible to predict the nucleation-rate as a function of the crystallization temperature $T_{\mathrm{c}}$, according to the following classical equation [xxxiv]:

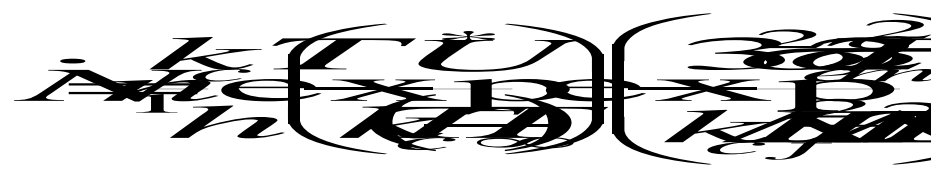

with $n_{1}$ the number of accessible sites (4 to 6 ), the lateral surface energy $\sigma=9.9 .10^{-7} \mathrm{~J}_{\mathrm{cm}} \mathrm{cm}^{-2}$ $[\mathrm{xxxv}]$, and the extremity surface energy $\sigma_{\mathrm{e}}=26.8 .10^{-7}{\mathrm{~J} . \mathrm{cm}^{-2}}^{-\mathrm{xxxvi}}$, the equilibrium melting temperature $T_{\mathrm{m}}=579.2 \mathrm{~K}$ [36], the undercooling $\Delta T=T_{\mathrm{m}}-T_{\mathrm{c}}$, the melting enthalpy $\Delta H_{\mathrm{f}}=137 \mathrm{~J} \cdot \mathrm{g}^{-1}[36]$, the activation energy $U^{*}=6270 \mathrm{~J} \cdot \mathrm{mol}^{-1}$ and $T_{\infty}=T_{\mathrm{g}}-30 \mathrm{~K}$ [xxxvii]. In our case, the model predicts a negligible nucleation-rate at high crystallization temperature (down to $200{ }^{\circ} \mathrm{C}$ ) and an increase of it with undercooling down to $T_{\mathrm{c}}=155{ }^{\circ} \mathrm{C}$ (temperature for maximal $N$ ). For all the samples, independently from their nature (homopolymer, copolymer, blend, modified blend), POM studies showed a nucleation activated at temperature higher than $240{ }^{\circ} \mathrm{C}$ (Table 5). All the nuclei are activated in a narrow temperature range (this is the reason why almost all the spherulites inside a sample have the same size), no new nuclei are activated after this initial nucleation. All these observations are incompatible 
with a homogeneous nucleation and rather indicative of heterogeneous processes. Hence, albeit all the materials were carefully purified, the presence of trace impurities that could be responsible -to some extent or even in totality- of the heterogeneous nucleation cannot be ruled out. Yet, it is worth noting that the concentration of these trace impurities is, by nature, unpredictable and irreproducible; therefore, its effect on the crystallization behavior should be differentiated and should feature a random character as well. For all the block copolymers prepared in this study, a monotonous decrease of the crystallization temperature with the increase of aPS fraction in the copolymer was systematically observed; also, at a given aPS/sPS ratio, the $T_{\mathrm{c}}$ value was found to be always higher than that of the corresponding blend (Figure S8). Moreover, the crystallization trend sPS $>$ sPS- $b$-aPS $\sim$ blends modified with sPS- $b$-aPS $>$ sPS/aPS blends was always verified. Therefore, despite the careful purification and control experiments [Erreur ! Signet non défini.], whether impurities do or do not significantly act as heterogeneous nucleating agents, accounting for the quite large differences in nuclei densities observed between block copolymers and blends (simple and modified ones), is still an open issue.

A third, alternative hypothesis to account for the faster crystallization rate of block copolymers would relate to intrinsic thermodynamic factors. Indeed, the chemical bond between the atactic and syndiotactic blocks may be anticipated to result in a slight reduction of the chain entropy of both segments (including the crystalline sPS one) inside the melt. It is however difficult at this stage to speculate on the significance and possible impact of such factors.

\section{Concluding Remarks}

In conclusion, the thermal properties of block copolymers and blends made of the same components (sPS and aPS), with identical composition and molecular weights, have been investigated for the first time. The role of the block copolymer as an additive in the blend has 
been also studied. DSC studies performed under both isothermal and non-isothermal conditions, independently confirmed by POM studies, led to a clear trend for the crystallization rate at a given sPS/aPS ratio ( $c a .50: 50$ and 20:80): sPS $>$ sPS- $b$-aPS $\sim$ sPS/aPS blends modified with sPS- $b$-aPS copolymers $>$ sPS/aPS blends. The faster crystallization of the copolymers cannot be ascribed to the polymorphism of sPS since in all the samples, independently from their nature (homopolymer, copolymer, blend or modified blend) sPS showed always the same crystalline $\beta$ form. An heterogeneous nucleation, to be connected with quite different nuclei densities between block copolymers vs. blends and modified blends, has been demonstrated; however, the exact implication of trace impurities in those polymers remains unclear. A possible intrinsic role of the chemical bond existing between the aPS and sPS blocks has been hypothesized.

A most important finding of this study probably relates to the crystallization mechanisms. In the case of copolymers, this mechanism proved identical at each aPS/sPS composition, that is a regular nucleation and crystalline growth mechanism controlled by an interfacial process. In the case of blends, two different mechanisms were evidenced: at 50:50 aPS/sPS ratio, blends crystallize via a regular nucleation/crystalline-growth mechanism, while blends with higher aPS contents (80:20 aPS/sPS) crystallize through spinodal decomposition.

Finally, the addition of a block copolymer in blends resulted in a faster crystallization of these modified blends; the latter blends crystallize via a mechanism dependent on the aPSconcentration, as observed for the corresponding unmodified blends. The presence of a small amount of such block copolymer in a aPS/sPS blend containing only 10-20\% of sPS allows to avoid the depression of the melting transition and generate materials where the crystallinity of sPS is preserved. This finding is potentially much interesting from an industrial point of view and opens avenues for the preparation of tailor-made "composite" PS materials. 
Supporting Information Available. Detailed tables and complementary figures on the thermal characterization of all sPS homopolymers, sPS/aPS blends, sPS- $b$-aPS block copolymers; experimental details and methodology used for POM analyses and additional POM pictures.

Acknowledgements. We are grateful to Total Petrochemicals for financial support of this work (grant to LA).

References

and

Notes

[ ] Maul J, Frushour BG, Kontoff JR, Eichenauer H, Ott KH, Schade C. Polystyrene and Styrene Copolymers, in: Ullmann's Encyclopedia of Industrial Chemistry, 2007, Wiley-VCH Ed., Weinheim.

ii [ ] (a) Schellenberg J. Syndiotactic Polystyrene, 2010, Wiley Ed., Hoboken, New Jersey, US. (b) Polymer Data Handbook, p. 832, 1999 Oxford Univ. Press. Inc.

iii [ ] (a) Wang C, Fan YD, Chen, CC, Hung CH. Macromol. Chem. Phys. 2007; 208: 2428. (b) Ma WM, Yu J, He JS. J. Polym. Sci. Part B: Polym. Phys. 2007; 45: 1755. (c) Wang C, Lin CC, Chu CP. Macromolecules, 2006; 39: 9267. (d) Chiu FC, Lau CS. J. Polym. Sci. Part B: Polym. Phys. 2006; 44: 2798. (e) Wang C, Lin CC, Tseng LC. Polymer 2006; 47: 390. (f) Wang C, Wang ML, Fan YD. Macromol. Chem. Phys. 2005; 206: 1791. (g) Wang C, Liao WP, Cheng YW, Lin, TL. Polymer 2004; 45: 961. (h) Wang C, Liao WP, Wang ML, Lin CC. Polymer 2004; 45: 973. (i) Sun YS, Woo EM, Wu MC, Ho RM. Macromolecules, 2003; 36: 8415. (j) Wang C, Chen CC, Cheng YW, Liao WP, Wang ML. Polymer 2002; 43: 5271. (k) Sun YS, Woo EM. J. Polym. Sci. B: Polym. Phys. 2002; 40: 176. (1) Sun YS, Woo EM. Polym. Mater. Sci. Eng. 2001; 85: 551. (m) Park JY, Kwon MH, Park OO. J. Polym. Sci. Part B: Polym. Phys. 2000; 38: 
3001. (n) Wu FS, Woo EM. Polym. Eng. Sci. 1999; 39: 825. (o) Bonnet M, Buhk M, Petermann J. Polym. Bull. 1999; 42: 353. (p) Woo EM, Wu FS. J. Polym. Sci. B: Polym. Phys. 1998; 36: 2725. (q) Woo EM, Wu FS. Macromol. Chem. Phys. 1998; 199: 2041.

(a) Chiu FC, Peng CC. Polymer 2002; 43: 4879. (b) Woo EM, Lee ML, Sun YS. Polymer 2000; 41: 883. (c) Hong BK, Jo WH, Kim J. Polymer 1998; 39: 3753. (d) Bonnet M, Buhk M, Trogner G, Rogausch KD, Petermann J. Acta Polym. 1998; 49: 174. (e) Watanabe T, Zhang GZ, Yoshida HY, Kawai T. J. Therm. Anal. Cal. 2003; 72: 57.

[ ] Annunziata L, Sarazin Y, Duc M, Carpentier JF. Macromol. Rapid Commun. $2011 ; 32: 751$.

vi [ ] Mena M, Royo P, Serrano R. Organometallics 1989; 8: 476. 1940, 8, 212. (c) Avrami M. J. Chem. Phys. 1941; 9:177.

ix [ ] The relative crystalline volumetric fraction $V_{c}$ can be calculated from:

$$
\mathrm{V}_{\mathrm{c}}=\mathrm{W}_{\mathrm{c}} /\left[\mathrm{W}_{\mathrm{c}}+\left(\rho_{\mathrm{c}} / \rho_{\mathrm{a}}\right) \times\left(1-\mathrm{W}_{\mathrm{c}}\right)\right]
$$

where $\rho_{\mathrm{c}}$ and $\rho_{\mathrm{a}}$ are densities of the fully crystalline and amorphous polymers, respectively. In this case, values of $\rho_{c}=1.05$ and $\rho_{a}=1.11$ were used.Erreur ! Signet non défini. ${ }^{b} \mathrm{~W}_{\mathrm{c}}$ is the crystalline mass fraction that can be calculated as:

$$
\mathrm{W}_{\mathrm{c}}=\Delta \mathrm{H}(t) / \Delta \mathrm{H}(\text { total })
$$

See: Lorenzo, A. T., Arnal, M. L., Albuerne, J., Muller A. J., Polymer Test. 2007; 26: 222.

$x$ [ ] The dependence of the crystallization rate on the molecular weight has been investigated by Wesson for sPS samples with molecular weights significantly higher than those reported in the present study $\left(M_{\mathrm{w}}=348,000-803,000 \mathrm{~g} \cdot \mathrm{mol}^{-1}\right)$. In such a 
range, the lower molecular weight sPS showed the fastest crystallization at lower temperatures, while, at higher temperatures, the higher molecular weight sPS crystallized the fastest. See: Wesson RD. Polym. Eng. Sci. 1994; 34: 1157.

xi [ ] Yang J, Mc Coy B, Madras GJ. J. Chem. Phys. 2005; 122: 4901 and references cited therein.

xii [ ] De Rosa C, Ruiz de Ballesteros O, Di Gennaro M, Auriemma F. Polymer 2003; 44: 1861.

[ ] (a) Guerra G, Vitagliano VM, De Rosa C, Petraccone V, Corradini P. Macromolecules 1990; 23: 1539. (b) Chatani Y, Shimane Y, Inoue Y, Inagaki Y, Ishioka T, Ijitsu T, Yukimori H. Polymer 1992; 33: 488. (c) Rizzo P, Albunia AR, Guerra G. Polymer 2005; 46: 9549. (d) D'Aniello C, Rizzo P, Guerra G. Polymer 2005; 46: 11435 .

[ ] (a) De Rosa C, Guerra G, Petraccone V, Corradini P. Polym. J. 1991; 23: 1435.

(b) Corradini P, De Rosa C, Guerra G, Napolitano R, Petraccone V, Pirozzi B. Eur. Polym. J. 1994, 30, 1173. (c) Cartier L, Okihara T, Lotz B. Macromolecules 1998; 31: 3303.

De Rosa C, Rapacciuolo M, Guerra G, Petraccone V, Corradini P. Polymer 1992; 33: 1423.

(a) Rizzo P, Lamberti M, Albunia AR, Ruiz de Ballesteros O, Guerra G. Macromolecules 2002; 35: 5854. (b) Immirzi A, De Candia F, Iannelli P, Vittoria V, Zambelli A. Makromol. Chem. Rapid Commun. 1988; 9: 761. 
Tsujita Y. J. Polym. Sci. B: Polym. Phys. 2005; 43: 1873. (d) Gowd EB, Tashiro K, Ramesh C. Prog. Polym. Sci. 2009; 34: 280.

Xviii

[ ] (a) Rizzo P, Daniel C, De Girolamo A, Del Mauro A, Guerra G. Chem. Mater. 2007; 19: 3864. (b) Petraccone V, Ruiz de Ballesteros O, Tarallo O, Rizzo P, Guerra G. Chem. Mater. 2008; 20: 3663. (c) Rizzo P, D'Aniello C, De Girolamo A. Del Mauro A, Guerra G. Macromolecules 2007; 40: 9470.

(a) De Candia F, Ruvolo A, Vittoria V. Makromol. Chem. Rapid. Commun. 1991; 12: 295. (b) Petraccone V, Auriemma F, Dal Poggetto F, De Rosa C, Guerra G, Corradini P. Makromol Chem 1993; 194: 335. (c) Auriemma F, Petraccone V, Dal Poggetto F, De Rosa C, Guerra G, Manfredi C, Corradini P. Macromolecules 1993; 26: 3772. (d) Rizzo P, Albunia AR, Guerra G. Macromol. Chem. Phys. 2009; 210: 2148.

(a) Manfredi C, De Rosa C, Guerra G, Rapacciuolo M, Auriemma F, Corradini P. Macromol. Chem. Phys. 1995; 196: 2795. (b) Manfredi C, Guerra G, De Rosa C, Busico V, Corradini P. Macromolecules 1995; 28: 6508.

[ ] (a) Chatani Y, Inagaki Y, Shimane Y, Ijitsu T, Yukimori H, Shikuma H. Polymer 1993; 34: 1620. (b) Chatani Y, Inagaki T, Shimane Y, Shikuma H. Polymer 1993; 34: 4841. (c) De Rosa C, Rizzo P, Ruiz de Ballesteros O, Petraccone V, Guerra G. Polymer 1999; 40: 2103. (d) Tarallo O, Petraccone V. Macromol. Chem. Phys. 2004; 205: 1351. (e) Tarallo O, Petraccone V. Macromol. Chem. Phys. 2005; 206: 672. (f) Daniel C, Galdi N, Montefusco T, Guerra G. Chem. Mater. 2007; 19: 3302. (g) Albunia AR, D'Aniello C, Guerra G. Cryst. Eng. Comm. 2010; 12: 3942. (h) Tarallo O, Petraccone V, Albunia A. R, Daniel C, Guerra G. Macromolecules 2010; 43: 8549. (i) Musto P, Rizzo P, Guerra G. Macromolecules 2005; 38: 6079. 
(a) Petraccone V, Tarallo O, Venditto V, Guerra G. Macromolecules 2005; 38:

6965. (b) Tarallo O, Petraccone V, Venditto V, Guerra G. Polymer 2006; 47: 2402. (c)

Malik S, Rochas C, Guenet J. M. Macromolecules 2006; 39: 1000. (d) Galdi N, Albunia AR, Oliva L, Guerra G. Macromolecules 2006; 39: 9171.

xxiv [ ] Kaji K, Nishida K, Kanaya T, Matsuba G, Konishi T, Imai M. Adv. Polym. Sci. 2005; 191: 187.

(a) Takebe T, Yamasaki K., Chap. 11, in Syndiotactic Polystyrene, Schellenberg, J. (Editor) 2010, Wiley Ed., Hoboken, New Jersey, US. (b) Wang C, Lin CC, Chu CP. Polymer 2005; 46: 12595. (c) Woo EM, Sun YS, Lee ML. Polymer 1999; 40: 4425 .

xxvi [ ] Repeated attempts to identify entities enabling an accurate determination of the crystallization growth rate for Blend-4 were unsuccessful. spherulites increased by a factor 3 from $\mathrm{T}=245^{\circ} \mathrm{C}$ till the end of the crystallization, i.e. $\mathrm{T}<235{ }^{\circ} \mathrm{C}$. This variation remains however weak and is still consistent with an almost instantaneous nucleation.

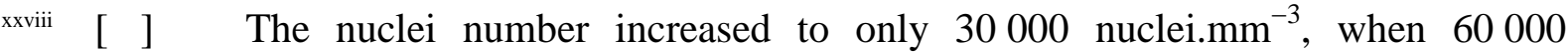
nuclei.mm ${ }^{-3}$ should be expected from a simple mixing rule (i.e., density $\times$ fraction content $=430000 \times 0.15)$

xxix [ ] Chiu FC, Li MT. Polymer 2003; 44: 8013.

[ ] Nucleation of sPS in the $\beta$ phase has been reported, in some cases, to be homogeneous for crystallization from the melt; see: Woo EM, Yang CP. Prog. Polym. Sci. 2001, 26, 945. 
crystallization experiments. Also, additional DSC experiments under non-isothermal conditions by changing the $\mathrm{T}_{\max }$ were performed on a 50:50 sPS/aPS blend, intentionally "contaminated" with $20 \mathrm{wt} \%$ of $\mathrm{CuBr} /$ pentamethyldiethylentetramine (PMDETA), that is the catalytic system used to generate the aPS block in the copolymers; the other trace impurities, possibly remaining from the synthesis of the sPS block despite the purification process, should be present also in the homo sPS (sPS-1) and the sPS sample used to prepare the blends, as the catalytic system is always the same $\mathrm{Cp}^{*} \mathrm{TiBn}_{3} / \mathrm{B}\left(\mathrm{C}_{6} \mathrm{~F}_{5}\right)_{3 .}$. At different $\mathrm{T}_{\max }$ of 300 and $335^{\circ} \mathrm{C}$, the above blend "deliberately contaminated" with CuBr/PMEDTA showed similar values of $\mathrm{T}_{c}$ (Table S6). These control experiments suggest that impurities, possibly originating from residual catalyst, are present at very low levels and do not affect significantly these crystallization data. On the other hand, their actual presence and possible implication in the observed instantaneous, heterogeneous nucleation cannot be completely ruled out. [ ] For crystallization induced by impurities, see: (a) Difiore, C, Leone, B, DeRosa, C, Guerra, G, Petraccone, V, Didino, G, Bianchi, R, Vosa, R J. Appl. Polym. Sci. 1993, 48, 1997. (b) Achillias, DS, Papageorgiou, GZ, Karayannidis, GP J. Polym. Sci. Part B: Polym. Phys. 2004, 42, 3775. (c) Lommerts, BJ Polymer 2001, 42, 6283. (d) Hong, SM, Choi, SH, Lee, CH, Hwang, SS, Kim, KU, Cho, I Polym. J. 2000, 32, 187.

[ ] It is known that exfoliated nanoclays or carbon nanocapsules enhances nucleation of the sPS $\beta$-phase; see for example: (a) Tseng, CR; Lee, HY; Chang, FC J. Polym. Sci., Polym. Phys. 2001, 39, 2097. (b) Tseng, CR; Wu, JY; Lee, HY; Chang, FC Polymer 2001, 42, 10063. (c) Wu, TM; Hsu, SF; Wu, JY J. Polym. Sci., Polym. Phys. 2002, 40, 736. (d) Wu, TM; Hsu, SF; Wu, JY J. Polym. Sci., Polym. Phys. 2003, 41, 560. (e) Wang, C; Huang, CL; Chen, YC; Hwang, GL; Tsai, SJ Polymer 2008, 49, 5564. xxxiv [ ] Lauritzen JI, Hoffman JD. J. Res. Natl. Bur. Stand. Sect. A 1960, 64, 73. xxxv [ ] Wang C, Chen CC, Hung CH, Lin KS. Polymer 2004, 45, 6681. 
xxxwi [ ] Su CH, Jeng U, Chen SH, Cheng CY, Lee JJ, Lai YH, Su WC, Tsai JC, Su AC.

Macromolecules 2009, 42, 4200.

xxxvii [ ] Suzuki T, Kovacs AJ. Polym. J. 1970, 1, 82. 


\section{Captions for Figures}

Figure 1. Effect of the molecular weights $\left(M_{\mathrm{n}}\right)$ of sPS (०) and aPS ( $\left.\mathbf{a}\right)$ on the crystallization temperature $\left(T_{\mathrm{c}},{ }^{\circ} \mathrm{C}\right)$ in 50:50 aPS/sPS blends (cooling rate $5^{\circ} \mathrm{C} / \mathrm{min}$ ).

Figure 2. Crystallization temperature $\left(T_{\mathrm{c}}\right)$ at different cooling rates as a function of the sPS fraction in aPS/sPS blends and sPS- $b$-aPS stereodiblock copolymers (Table 3 ).

Figure 3. Crystallization temperature $\left(T_{\mathrm{c}}\right)$ at different cooling rates as a function of the sPS fraction in aPS/sPS blends and in aPS/sPS blends modified with $15 \%$ of aPS- $b$-sPS copolymer Cop-1 (Table 3).

Figure 4. Plot of the reciprocal value of the crystallization peak time $\left(\mathrm{t}_{\mathrm{p}}{ }^{-1}\right)$ as a function of the crystallization temperature $\left(T_{\mathrm{c}}\right)$ determined by isothermal DSC studies for a pristine sPS (sPS1), a aPS/sPS blend (Blend-2), a aPS- $b$-sPS stereodiblock copolymer (Cop-1) and a aPS/sPS blend modified with a aPS- $b$-sPS stereodiblock copolymer (Blend-2-mod); all materials had a ca. 50:50 aPS/sPS composition.

Figure 5. Avrami plots determined at $244^{\circ} \mathrm{C}$ by isothermal DSC studies for a prisitine sPS (sPS-1), a regular aPS/sPS blend (Blend-2), a aPS- $b$-sPS stereodiblock copolymer (Cop-1), and a aPS/sPS blend modified with $15 \%$ of a sPS- $b$-aPS copolymer (Blend-2-mod); all materials had a $c a$. 50:50 aPS/sPS composition.

Figure 6. Dependence of the crystallization temperature $\left(T_{\mathrm{c}}\right) v s . T_{\max }$ determined by isothermal DSC studies for a aPS/sPS blend (Blend-2), a aPS- $b$-sPS stereodiblock copolymer 
(Cop-1) and a aPS/sPS blend modified with a aPS- $b$-sPS stereodiblock copolymer (Blend-2mod); all materials had a similar ca. 50:50 aPS/sPS composition (cooling rate: $-20{ }^{\circ} \mathrm{C} \cdot \mathrm{min}^{-1}$ ).

Figure 7. WAXRD patterns of a regular aPS/sPS blend (bottom; Blend-2), a aPS/sPS blend modified with $15 \%$ of sPS- $b$-aPS (middle; Blend-2-mod), and a aPS- $b$-sPS stereodiblock copolymer (top; Cop-1); all materials have a similar ca. 50:50 aPS/sPS composition.

Figure 8. WAXRD patterns of a regular aPS/sPS blend (bottom; Blend-6), a aPS/sPS blend modified with $15 \%$ of sPS- $b$-aPS (middle; Blend-6-mod), and a aPS- $b$-sPS stereodiblock copolymer (top; Cop-3); all materials have a similar ca. 90:10 aPS/sPS composition.

Figure 9. Conversion-rate deduced from light intensity variation measured by POM (conducted at constant cooling-rate $\mathrm{d} T / \mathrm{dt}=-10{ }^{\circ} \mathrm{C} \cdot \mathrm{min}^{-1}$ ) for homopolymer sPS-1, block copolymers Cop-1 and Cop-2, sPS-aPS Blend-2 and Blend-4, and a sPS-aPS blend modified by a sPS- $b$-aPS stereodiblock copolymer (Blend-2-mod).

Figure 10. POM pictures of the crystallization step ( $12 \pm 3 \%$ conversion): (a) sPS-1 ( $T=247$ $\left.{ }^{\circ} \mathrm{C}\right)$; (b) Cop-2 $\left(T=235{ }^{\circ} \mathrm{C}\right)$; (c) Blend-4 $\left(T=240{ }^{\circ} \mathrm{C}\right)$; (d) Blend-4-mod $\left(T=238{ }^{\circ} \mathrm{C}\right)$. A quarter of original pictures is shown here to show more precisely the growing morphologies.

Figure 11. Increase of the diameter and of the depolarized intensity of a spherulite inside Blend- 2 as a function of the temperature at constant cooling-rate $\left(\mathrm{dT} / \mathrm{dt}=-10^{\circ} \mathrm{C} \cdot \mathrm{min}^{-1}\right)$.

Figure 12. Increase of the light intensity along the line defined in Figure 16 in Blend-4 as a function of temperature at constant cooling-rate $\left(\mathrm{d} T / \mathrm{dt}=-10^{\circ} \mathrm{C} \cdot \mathrm{min}^{-1}\right)$. 
Figure 13. Thermal dependence of the growth-rate of homopolystyrene sPS-1 ( $\square$ ), aPS- $b$-sPS block copolymers Cop-1 (○) and Cop-2 ( $\mathbf{\Delta})$, aPS/sPS Blend-2 (•), modified aPS/sPS Blend2-mod $(\triangle)$, as determined by polarized optical microscopy, and previous literature data [Erreur ! Signet non défini.] for pristine sPS (+, solid line). 